\title{
Clinical efficacy and treatment persistence of monthly minodronate for osteoporotic patients unsatisfied with, and shifted from, daily or weekly bisphosphonates: the BP-MUSASHI study
}

\author{
A. Sakai • S. Ikeda $\cdot$ N. Okimoto $\cdot$ H. Matsumoto • \\ K. Teshima $\cdot$ Y. Okazaki $\cdot$ F. Fukuda $\cdot$ S. Arita $\cdot$ \\ H. Tsurukami • M. Nagashima $・$ T. Yoshioka
}

Received: 4 March 2014 / Accepted: 7 May 2014 / Published online: 5 June 2014

(C) The Author(s) 2014. This article is published with open access at Springerlink.com

\begin{abstract}
Summary This multi-center, prospective, open-label, observational study evaluated the effects of once-monthly minodronate $(50 \mathrm{mg})$ on treatment persistence, bone turnover markers, bone mineral density, low back pain, and upper gastrointestinal symptoms in outpatients with osteoporosis previously treated with daily or weekly bisphosphonate products.

Introduction The purposes of this study were to investigate the effects of once-monthly oral minodronate (MIN $50 \mathrm{mg}$ ) on bone turnover markers and bone mineral density, low back pain, and upper gastrointestinal symptoms, as well as preference for and treatment persistence of MIN $50 \mathrm{mg}$ among
\end{abstract}

Japanese osteoporosis patients currently treated with daily or weekly bisphosphonates.

Methods Study patients were allocated based on their preference to either the Switch group (patients willing to switch over to MIN $50 \mathrm{mg}$ ) or the Continue group (patients wanting to continue their current therapies). Patients' treatment persistence and satisfaction levels with the therapies were assessed using a self-administered questionnaire. The study endpoints were serum TRACP-5b, serum P1NP, bone mineral density, upper gastrointestinal symptoms, and low back pain.

Results In total, 264 and 133 patients were allocated into the Switch and Continue groups, respectively. Approximately, $65 \%$ of patients were willing to switch to MIN $50 \mathrm{mg}$, with

\section{A. Sakai $(\square)$}

Department of Orthopaedic Surgery, School of Medicine, University of Occupational and Environmental Health, 1-1 Iseigaoka,

Yahatanishi-ku, Kitakyushu 807-8555, Japan

e-mail: a-sakai@med.uoeh-u.ac.jp

S. Ikeda

Department of Orthopaedic Surgery, Ken-Ai Memorial Hospital, Onga, Japan

N. Okimoto

Okimoto Clinic, Kure, Japan, Okamoto Orthopaedics and Sports

Clinic, Hiroshima, Japan

H. Matsumoto

Department of Orthopaedic Surgery, Sanzai Hospital, Saito, Japan

K. Teshima

Teshima Orthopaedic Clinic, Kitakyushu, Japan

Y. Okazaki

Department of Orthopaedic Surgery, Makiyama Central Hospital,

Fukuoka, Japan

\author{
F. Fukuda \\ Department of Orthopaedic Surgery, Kitakyushu General Hospital, \\ Kitakyushu, Japan \\ S. Arita \\ Department of Orthopaedic Surgery, Obase Hospital, Miyako, Japan \\ H. Tsurukami \\ Tsurukami Clinic of Orthopaedic and Rheumatology, \\ Kumamoto, Japan
}

M. Nagashima

Katsuki Neurosurgery and Orthopaedic Clinic, Nogata, Japan

T. Yoshioka

Department of Orthopaedic Surgery, Sakamidorii Hospital,

Hiroshima, Japan 
the predominant reason being "less frequent dosing more convenient." Treatment persistence was significantly higher in the Switch group (MIN $50 \mathrm{mg}$ ) than the Continue group. Almost all patients with abnormal bone metabolism markers demonstrated normalization after switchover. MIN $50 \mathrm{mg}$ alleviated low back pain and upper gastrointestinal symptoms induced by prior bisphosphonate use.

Conclusions MIN $50 \mathrm{mg}$ alleviates low back pain, reduces bone turnover markers and increases bone density, and induces fewer upper gastrointestinal symptoms after switchover from prior bisphosphonate products, and therefore, it may provide patients with a more convenient treatment option and enhance long-term treatment persistence.

Keywords Bone mineral density $\cdot$ Minodronate $\cdot$ Once monthly $\cdot$ Persistence $\cdot$ Preference $\cdot$ TRACP-5b

\section{Introduction}

Bisphosphonates (BPs) are recommended as a first-line agent for osteoporosis treatment by many national and international guidelines [1-3]. However, the treatment persistence rate of BPs is far from satisfactory owing to its complex administration regimen and patients' poor awareness levels of osteoporosis [4-9]. New drug formulations with less frequent dosing to resolve these problems have been developed, and weekly BP products have become mainstream in Japan, while monthly BPs are already familiar outside Japan. In September 2011, the first novel, once-monthly $50 \mathrm{mg}$ formulation of minodronate (MIN $50 \mathrm{mg}$ ) was approved and marketed in Japan.

Minodronate is a third-generation bisphosphonate agent containing nitrogen [10] and approved for use for the treatment of osteoporosis in Japan [11]. Its mechanism of action involves inhibition of farnesyl pyrophosphate synthase activity [12], and therefore, MIN $50 \mathrm{mg}$ shows strong inhibitory effects on bone resorption [13]. In an earlier clinical study, Okazaki et al. [14] reported that monthly minodronate at a dose of 30 or $50 \mathrm{mg}$ had comparable efficacy to $1 \mathrm{mg}$ daily administration in terms of change in bone mineral density (BMD) and bone turnover markers, with similar safety profiles.

The purposes of this multi-center, prospective, open-label, observational study were to investigate (1) the effects of oncemonthly oral BP (MIN $50 \mathrm{mg}$ ) on bone turnover markers and bone mineral density (BMD), (2) analgesic effects of MIN $50 \mathrm{mg}$ on low back pain (LBP) and upper gastrointestinal (GI) symptoms, and (3) preference for and treatment persistence of MIN $50 \mathrm{mg}$ among Japanese patients with osteoporosis currently treated with daily or weekly bisphosphonates. Based on the findings of this study, we discuss the contribution of the once-monthly product to improving treatment persistence in outpatients with osteoporosis compared to treatment with conventional BP products.

\section{Material and methods}

This study was approved by the institutional review board at each participating study site. Prior to commencing any study procedure, the purposes and methods of this study were explained to all participants, and their written informed consent was obtained.

\section{Study design}

This observational study was conducted based on a multicenter, prospective, open-label, parallel-group comparison design, in outpatients with osteoporosis currently treated with daily or weekly BPs, at 11 institutions in Japan. A questionnaire form was used for data collection.

A total of 397 patients were enrolled in the study from October 2011 to April 2012 and asked their preference for once-monthly oral bisphosphonate for group allocation. Registered patients were allocated based on their answered preferences to either the "Switch" group $(n=264)$, consisting of patients who were willing to switch over to MIN $50 \mathrm{mg}$ from their current therapies, or the "Continue" group $(n=133)$, consisting of patients who wanted to continue their current therapies (Fig. 1).

\section{Study endpoints and schedule}

The study endpoints were measured according to the following schedule: serum TRACP-5b (courtesy of DS Pharma Biomedical Co., Ltd., Tokyo, Japan), a bone resorption marker, at baseline and at 1,2, and 6 months after the start of the study; serum P1NP, a bone formation marker, at baseline and at 2 and 6 months after the start of the study; and BMD of the lumbar spine, total hip, femoral neck, and/or $1 / 3$ distal radius, at baseline and at 6 months after the start of the study. Upper GI symptoms were assessed by patients using a six-point symptom severity scale, and LBP was evaluated using a $100-\mathrm{mm}$ visual analogue scale (VAS) and five items in the pain domain score of the Japanese Osteoporosis Quality of Life (JOQOL) Questionnaire [15]. Patients' treatment persistence and satisfaction levels with the therapies were assessed using a self-administered questionnaire.

The self-administered questionnaire included the following items: (1) patient preference for once-monthly BP (MIN $50 \mathrm{mg}$ ) and the reason for willingness or unwillingness to switch to MIN $50 \mathrm{mg}$; (2) desire for improvement over current BP treatment; (3) patient persistence with current BP treatment; (4) patient persistence with MIN $50 \mathrm{mg}$ over 6 months; and (5) satisfaction level in patients treated with MIN $50 \mathrm{mg}$ and the reason for willingness to continue the medication. 
Fig. 1 Study design and schedule. a Patients were asked to complete a self-administered questionnaire on the following items: (1) Patient preference for once-monthly BP (MIN $50 \mathrm{mg}$ ) and the reason for willingness or unwillingness to switch to MIN $50 \mathrm{mg}$. (2) Desire for improvement over current BP treatment. (3) Persistence of current BP treatment. b Bone turnover markers (TRACP-5b and P1NP) were evaluated only in the Switch group. c Abdominal symptom-related QOL was evaluated using the Izumo scale [16], a questionnaire to assess quality of life in patients with gastrointestinal symptoms

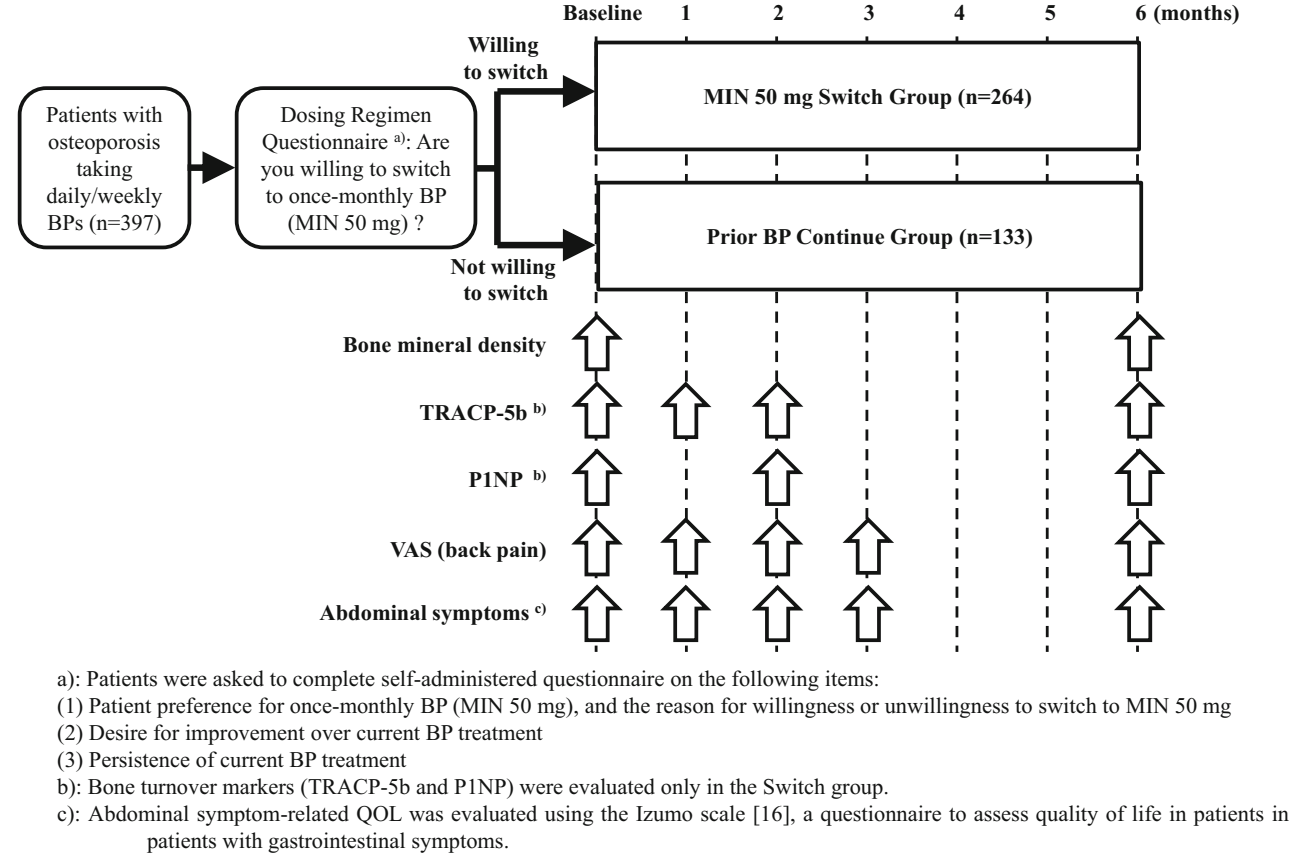

Statistical analysis

All obtained data were statistically analyzed by one author (AS) using JMP software ver. 8.2 (SAS Institute, Cary, NC, USA). Continuous variables were summarized as mean \pm standard deviation (SD), and categorical data were summarized as frequency and percentage (\%). Time course comparisons from baseline were evaluated using the Wilcoxon signed-rank test, group comparisons at specific time points using the Wilcoxon rank-sum test or Student's $t$ test, and comparisons of incidences using the chi-square test or Fisher's exact test. To assess treatment persistence, the data were illustrated as Kaplan-Meier survival curves according to treatment group and were analyzed using the log-rank test. All statistical tests were conducted with a significance level of $\alpha=0.05$, and no multiplicity adjustment was applied.

\section{Results}

A total of 397 patients using BPs for the treatment of osteoporosis were enrolled in the study. Study patients were divided into two study groups depending on their preference: patients in the Switch group $(n=264)$ were switched over to oncemonthly minodronate (MIN $50 \mathrm{mg}$ ), and those in the Continue group $(n=133)$ continued treatment with their current daily or weekly BP.

Baseline characteristics of study patients

The demographic and baseline characteristics of study patients are summarized in Table 1. Overall, patients' mean age was
76.0 years (range 54-98 y), and almost all study patients were female $(94.2 \%)$. The current bisphosphonate medication at baseline was predominantly a once-a-week product (78.8 \%). Nearly half of patients $(46.6 \%)$ had concomitant diseases, including hypertension, hyperlipidemia, and diabetes mellitus. The most common concomitant medications were vitamin D analogues $(57.7 \%)$ and calcium agents $(28.5 \%)$.

No significant differences were observed in the demographic characteristics of the Switch and Control groups. Among baseline characteristics, no significant differences were observed between the Switch and the Continue groups, except the VAS score for back pain $(27.9 \pm 20.8$ in the Switch group vs. $22.6 \pm 20.7$ in the Continue group; $p=0.010$ ).

With no statistically significant differences in the demographic and baseline characteristics between the groups, within-group comparisons were then conducted.

Patient preference and treatment persistence

Of 397 study patients, $264(66.5 \%)$ were willing to switch to MIN $50 \mathrm{mg}$, and 133 (33.5\%) were not willing to switch their current BP products. This trend, with two-thirds of patients willing to switch, was consistent across patients taking either daily or weekly BPs. In the daily dose subgroup, older patients showed a tendency to keep their current BP products. The most common reasons for willingness to switch to MIN $50 \mathrm{mg}$ were "less frequent dosing more convenient" $(87.3 \%)$ followed by "easier to remember to take medication" (54.8\%). By contrast, the most common reasons for unwillingness to switch to MIN $50 \mathrm{mg}$ were "being used to taking current product" (72.9\%) 
Table 1 Demographic and baseline characteristics of study patients

\begin{tabular}{|c|c|c|c|c|c|}
\hline Items & Unit & Total $(n=397)$ & Switch $(n=264)$ & Continue $(n=133)$ & $p$ value $^{\dagger}$ \\
\hline \multicolumn{6}{|l|}{ Demographic characteristics } \\
\hline Age & $\begin{array}{l}\text { Years } \\
(\min , \max )\end{array}$ & $\begin{array}{l}76.0 \pm 7.8 \\
(54,98)\end{array}$ & $\begin{array}{l}75.9 \pm 7.6 \\
(54,96)\end{array}$ & $\begin{array}{l}76.0 \pm 8.1 \\
(55,98)\end{array}$ & N. S. \\
\hline Sex & $\begin{array}{l}\text { Female } \\
(\%)\end{array}$ & $\begin{array}{l}374 \\
(94.2 \%)\end{array}$ & $\begin{array}{l}252 \\
(95.5 \%)\end{array}$ & $\begin{array}{l}122 \\
(91.7 \%)\end{array}$ & N. S. \\
\hline \multirow[t]{7}{*}{ Current bisphosphonate medication } & Daily regimen & $84(21.2 \%)$ & $54(20.5 \%)$ & $30(22.6 \%)$ & N. S. \\
\hline & Alendronate & 11 & 7 & 4 & \\
\hline & Risedronate & 5 & 2 & 3 & \\
\hline & Minodronate & 68 & 45 & 23 & \\
\hline & Weekly regimen & $313(78.8 \%)$ & $210(79.5 \%)$ & $103(77.4 \%)$ & N. S. \\
\hline & Alendronate & 228 & 157 & 71 & \\
\hline & Risedronate & 85 & 53 & 32 & \\
\hline \multirow[t]{2}{*}{ BMI } & $\left(\mathrm{kg} / \mathrm{m}^{2}\right)$ & $22.9 \pm 3.4$ & $23.0 \pm 3.5$ & $22.5 \pm 3.1$ & N. S. \\
\hline & $(\min , \max )$ & $(14.4,34.3)$ & $(14.4,34.3)$ & $(16.9,32.9)$ & \\
\hline \multirow[t]{5}{*}{ Previous fracture } & Yes & $170(42.8 \%)$ & $106(40.2 \%)$ & $63(47.4 \%)$ & N. S. \\
\hline & Spine & 126 & 80 & 46 & N. S. \\
\hline & Hip joint & 17 & 8 & 9 & \\
\hline & Wrist joint & 15 & 12 & 3 & \\
\hline & Other & 22 & 14 & 8 & \\
\hline \multirow[t]{7}{*}{ Comorbidity } & Yes & $185(46.6 \%)$ & $118(44.7 \%)$ & $67(50.4 \%)$ & N. S. \\
\hline & Diabetes M. & 25 & 14 & 11 & N. S. \\
\hline & Renal disease & 3 & 1 & 2 & \\
\hline & Rheumatism & 10 & 4 & 6 & \\
\hline & Hyperlipidemia & 39 & 23 & 16 & \\
\hline & Hypertension & 119 & 74 & 45 & \\
\hline & Arteriosclerosis & 19 & 8 & 11 & \\
\hline \multirow[t]{11}{*}{ Concomitant medication } & Yes & $310(78.1 \%)$ & $206(78.0 \%)$ & $104(78.2 \%)$ & N. S. \\
\hline & Vitamin D & 229 & 154 & 75 & N. S. \\
\hline & Vitamin K & 22 & 13 & 9 & \\
\hline & Calcitonin & 8 & 8 & 0 & \\
\hline & Calcium agents & 113 & 84 & 29 & \\
\hline & PPI & 36 & 25 & 11 & N. S. \\
\hline & $\mathrm{H}_{2}$ blocker & 31 & 14 & 17 & \\
\hline & Gastroprotectives & 52 & 30 & 22 & \\
\hline & $\mathrm{PGE}_{2}$ derivatives & 26 & 19 & 7 & \\
\hline & NSAIDs & $66(16.6 \%)$ & $45(17.0 \%)$ & $21(15.8 \%)$ & N. S. \\
\hline & Glucocorticoids & $3(0.8 \%)$ & $3(1.1 \%)$ & $0(0.0 \%)$ & N. S. \\
\hline \multicolumn{6}{|l|}{ Baseline characteristics } \\
\hline \multirow[t]{2}{*}{ Back pain VAS score } & $(\mathrm{mm})$ & $26.1 \pm 20.9$ & $27.9 \pm 20.8$ & $22.6 \pm 20.7$ & $0.010^{*}$ \\
\hline & $(\min , \max )$ & $(0,80)$ & $(0,79)$ & $(0,80)$ & \\
\hline \multirow[t]{6}{*}{ Abdominal symptoms score } & Heartburn & $1.34 \pm 2.01$ & $1.38 \pm 1.98$ & $1.26 \pm 2.06$ & N. S. \\
\hline & $(\min , \max )$ & $(0,9)$ & $(0,8)$ & $(0,9)$ & N.S. \\
\hline & Epigastralgia & $0.85 \pm 1.75$ & $0.89 \pm 1.78$ & $0.76 \pm 1.68$ & N. S. \\
\hline & $(\min , \max )$ & $(0,13)$ & $(0,13)$ & $(0,8)$ & \\
\hline & Epigastric fullness & $1.22 \pm 1.97$ & $1.24 \pm 1.90$ & $1.17 \pm 2.11$ & \\
\hline & $(\min , \max )$ & $(0,10)$ & $(0,10)$ & $(0,10)$ & \\
\hline \multirow[t]{4}{*}{ BMD (lumbar spine) } & $\left(\mathrm{g} / \mathrm{cm}^{2}\right)$ & $0.768 \pm 0.139$ & $0.767 \pm 0.141$ & $0.770 \pm 0.136$ & N. S. \\
\hline & $(n)$ & $(247)$ & $(167)$ & $(80)$ & \\
\hline & (YAM\%) & $75.6 \pm 13.4$ & $75.6 \pm 13.7$ & $75.4 \pm 12.8$ & N.S. \\
\hline & $(n)$ & $(247)$ & $(167)$ & $(80)$ & \\
\hline \multirow[t]{4}{*}{ BMD (total hip) } & $\left(\mathrm{g} / \mathrm{cm}^{2}\right)$ & $0.617 \pm 0.098$ & $0.622 \pm 0.088$ & $0.611 \pm 0.110$ & N. S. \\
\hline & $(n)$ & (107) & $(56)$ & $(51)$ & \\
\hline & (YAM\%) & $70.7 \pm 11.2$ & $71.8 \pm 9.6$ & $70.3 \pm 12.8$ & N. S. \\
\hline & $(n)$ & $(107)$ & $(56)$ & $(51)$ & \\
\hline \multirow[t]{4}{*}{ BMD (femoral neck) } & $\left(\mathrm{g} / \mathrm{cm}^{2}\right)$ & $0.534 \pm 0.091$ & $0.527 \pm 0.087$ & $0.545 \pm 0.095$ & N. S. \\
\hline & $(n)$ & $(150)$ & $(88)$ & $(62)$ & \\
\hline & (YAM\%) & $66.6 \pm 10.3$ & $65.7 \pm 9.6$ & $67.9 \pm 11.1$ & N. S. \\
\hline & $(n)$ & $(150)$ & $(88)$ & $(62)$ & \\
\hline \multirow[t]{2}{*}{ BMD (distal radius) } & $\left(\mathrm{g} / \mathrm{cm}^{2}\right)$ & $0.455 \pm 0.072$ & $0.455 \pm 0.076$ & $0.453 \pm 0.062$ & N. S. \\
\hline & $(n)$ & $(60)$ & $(45)$ & $(15)$ & \\
\hline
\end{tabular}


Table 1 (continued)

\begin{tabular}{|c|c|c|c|c|c|}
\hline Items & Unit & Total $(n=397)$ & Switch $(n=264)$ & Continue $(n=133)$ & $p$ value $^{\dagger}$ \\
\hline & $\begin{array}{l}(\text { YAM\%) } \\
(n)\end{array}$ & $\begin{array}{l}69.9 \pm 11.1 \\
(60)\end{array}$ & $\begin{array}{l}70.0 \pm 11.7 \\
(45)\end{array}$ & $\begin{array}{l}69.7 \pm 9.6 \\
(15)\end{array}$ & N. S. \\
\hline
\end{tabular}

Data are expressed as mean \pm standard deviation unless otherwise indicated

$B M I$ body mass index, Diabetes $M$. diabetes mellitus, $P P I$ proton pump inhibitor, NSAID non-steroidal anti-inflammatory drug, VAS visual analogue scale, $B M D$ bone mass density, YAM young adult mean

${ }^{\dagger}$ Comparison between Switch group and Continue group

* Statistically significant $(\alpha=0.05)$ as analyzed by Wilcoxon rank-sum test

N. S. statistically not significant as analyzed by Wilcoxon rank-sum test or chi-square test

followed by "more chance to miss taking medication" (29.3\%) and "being satisfied with current BP" $(27.8 \%)$. The relationship between patients' willingness to switch to MIN $50 \mathrm{mg}$ and persistence of their prior BPs was investigated, revealing that patients who sometimes $(n=91)$ or often $(n=7)$ missed taking their current BPs $(83.7 \%, 82$ of 98$)$ were more willing to switch to MIN $50 \mathrm{mg}$ than those who were completely persistent with their current BP regimen $(60.8 \%, 178$ of 293) $(p<0.001)$.

\section{Response to once-monthly minodronate}

The early responses to once-monthly minodronate (MIN $50 \mathrm{mg}$ ) were evaluated by comparisons within the Switch group (change over time) or between the Switch and Continue groups.

\section{Changes in BMD after 6 months of treatment (Fig. 2)}

BMD in the Switch group, evaluated as the percentage of young adult mean values (YAM\%), was significantly increased in the lumbar spine $(1.5 \%, p<0.001)$ and distal radius $(1.1 \%, p<0.01)$. In the subgroups of patients who switched from alendronate and risedronate, BMD was significantly increased in the lumbar spine $(+1.1 \%, p<0.001$ and $+2.3 \%$, $p<0.01$, respectively). In the subgroup of patients who switched from daily doses of minodronate, BMD was significantly increased in the lumbar spine $(+3.2 \%, p<0.01)$. By contrast, no significant changes were observed in BMD in the total hip or the femoral neck in the Continue group or any of its subgroups.
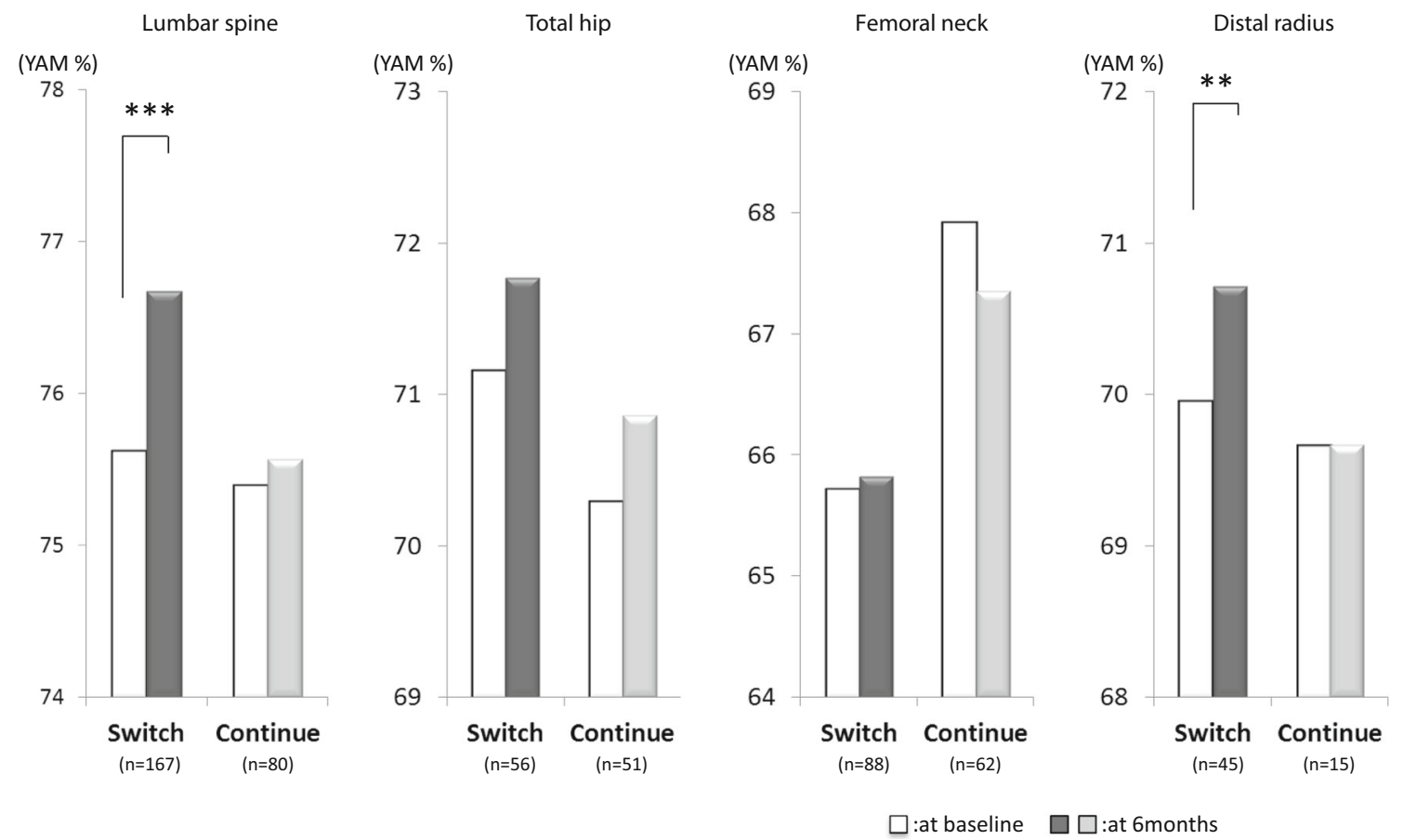

Fig. 2 Changes in BMD after 6 months of treatment. YAM\% young adult mean $(\%) * * p<0.01 ; * * * p<0.001$, significantly different from baseline as analyzed by Wilcoxon signed-rank test 
Changes in bone metabolism markers after 6 months of treatment (Fig. 3)

In the Switch group, the levels of the bone marker TRACP-5b (reference range 120 to $420 \mathrm{mU} / \mathrm{dL}$ ) significantly reduced within 1 month after treatment $(-10.2 \%, p<0.001)$ and at subsequent time points. Especially in the subgroup of patients with a higher baseline TRACP-5b (over $420 \mathrm{mU} / \mathrm{dL}$ ), TRACP-5b decreased rapidly (by approximately $30 \%$ ) into the reference range within 1 month after treatment. By contrast, in the subgroup of patients with normal baseline TRACP-5b levels, values were maintained within the reference range without any unwanted reductions throughout the study period.

A subgroup analysis was conducted for each prior BP medication. Patients with a high baseline TRACP-5b level $(>420 \mathrm{mU} / \mathrm{dL})$ in the subgroup switched over from alendronate showed the same trend as the Switch group overall, with a reduction of approximately $25 \%$. In the subgroup switched from risedronate, a larger reduction of approximately $35 \%$ was observed. In the subgroup switched from a daily dose of minodronate, a marked reduction of approximately $45 \%$ was observed but was not statistically significant due to the small number of patients.

The bone marker P1NP (reference range 14.9 to $68.8 \mu \mathrm{g} / \mathrm{L}$ ) was also significantly reduced within 2 months after treatment $(-8.4 \%, p<0.001)$ and at subsequent time points. Especially in the subgroup of patients with a higher baseline P1NP (over $68.8 \mu \mathrm{g} / \mathrm{L}$ ), P1NP decreased rapidly (approximately $55 \%$ ) into the reference range within 2 months after treatment. Similar to TRACP-5b, in the subgroup of patients with a normal baseline P1NP, values were maintained in the reference range without any unwanted reductions throughout the study period.

Changes in low back pain and upper gastrointestinal symptoms

Low back pain is well known as a common symptom of osteoporosis, and upper GI symptoms are common adverse drug reactions to BPs.

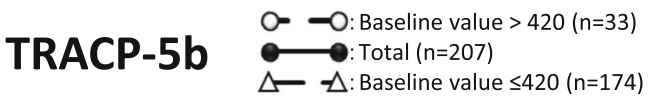
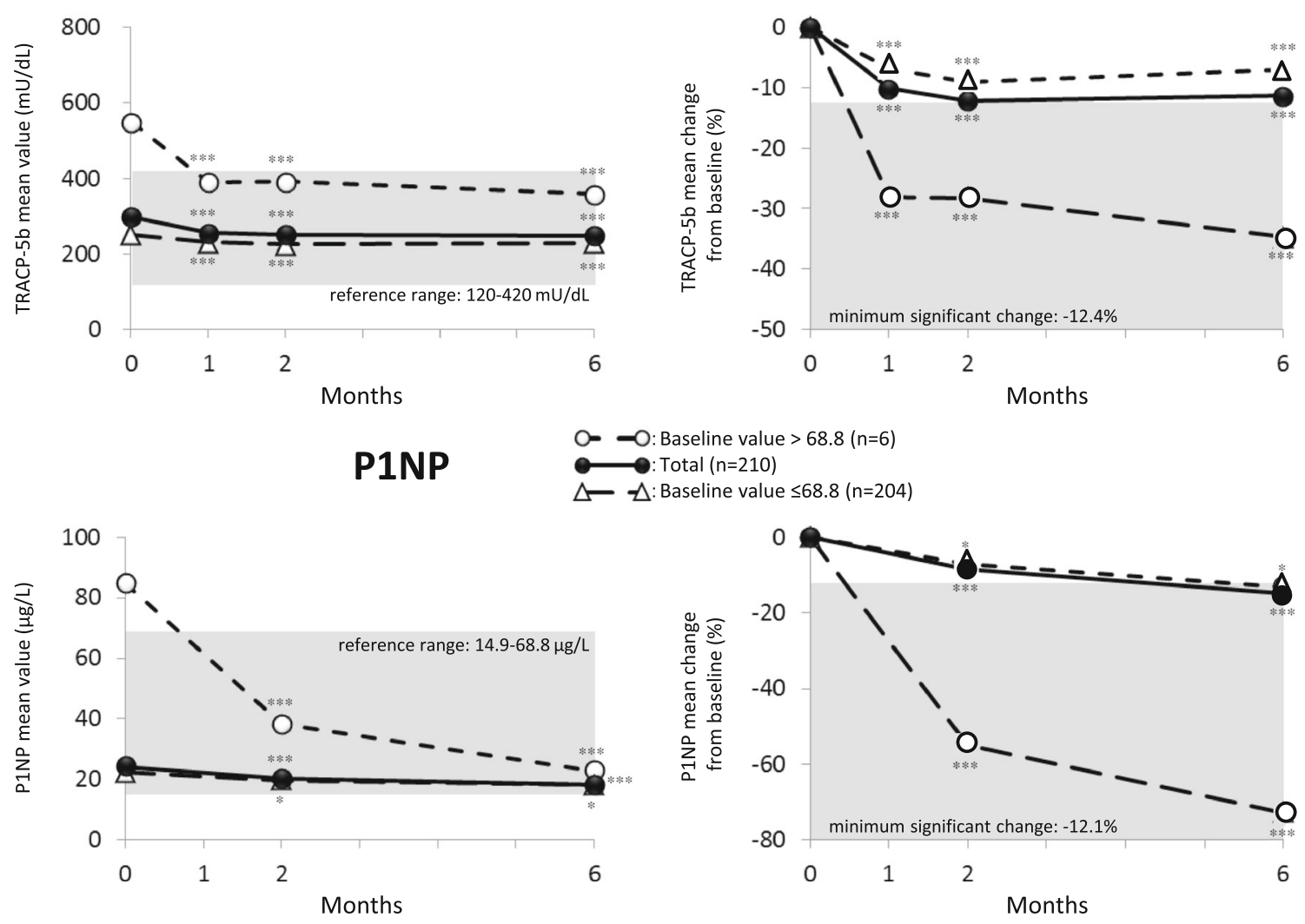

Fig. 3 Time course of change in TRACP-5b (upper) and P1NP (bottom) after switchover to MIN $50 \mathrm{mg}$. Data were evaluated in patients who completed the 6-month measurements. ${ }^{* *} p<0.001 ;{ }^{*} p<0.05$, significantly different from baseline as analyzed by Wilcoxon signed-rank test 
Fig. 4 Time course of change in back pain VAS score: a mean values at each evaluation point and $\mathbf{b}$ mean changes from baseline. VAS scores were evaluated in patients with baseline VAS scores $\geq 10 \mathrm{~mm}$ who completed 6-month VAS measurements. $+p<0.05 ;+++$ $p<0.001$, significantly different from values in the Continue group as analyzed by Wilcoxon ranksum test, $* * * p<0.001$, significantly different from baseline as analyzed by Wilcoxon signed-rank test a

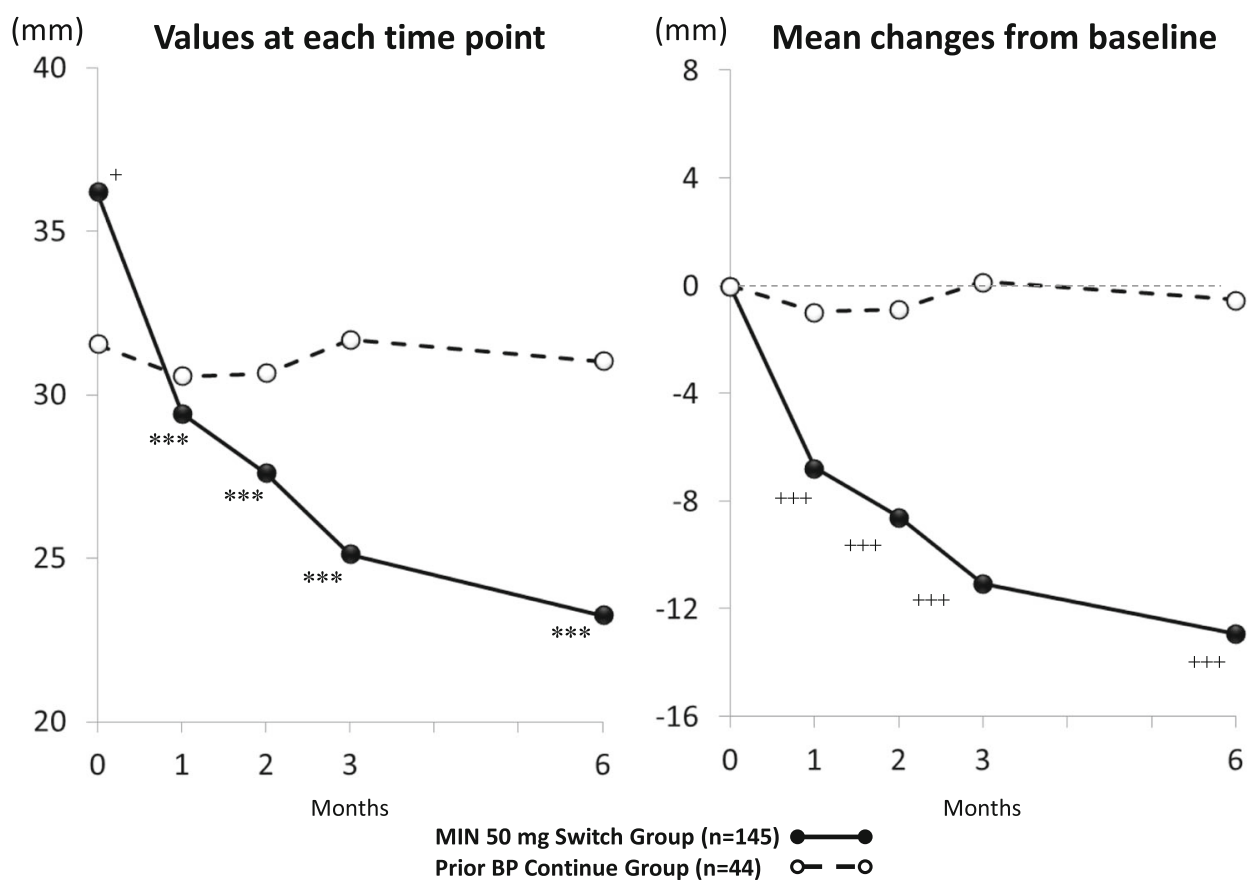

Changes in low back pain after 6 months of treatment (Fig. 4)

Low back pain was evaluated in patients with a baseline VAS score of $10 \mathrm{~mm}$ or more who completed all scheduled VAS measurements. The Switch and Continue groups consisted of 145 and 44 patients, respectively. The baseline mean VAS scores were $36.0 \pm 16.0 \mathrm{~mm}$ in the Switch group and $32.0 \pm 18.0 \mathrm{~mm}$ in the Continue group, which were significantly different $(p=0.046)$.

In the Switch group, VAS scores for low back pain significantly improved 1 month after treatment and at subsequent time points $(p<0.001)$. Also, the Switch group showed significantly greater decreases from baseline than the Continue group at 1 month after treatment and subsequent time points $(p<0.001)$. By contrast, in the Continue group, the VAS scores were stable, and therefore, the mean changes from baseline were not statistically significant throughout the study.

Subgroup analysis was conducted for each prior BP treatment (alendronate, risedronate, or daily dose of minodronate). In all subgroups, VAS scores demonstrated a decreasing trend after switching, with the decreases in the subgroups of patients who switched from alendronate and daily dose of minodronate statistically significant at 1 month after treatment and subsequent time points $(p<0.05)$. The Switch group showed significantly greater decreases from baseline than the Continue group only for the subgroup of patients who switched from alendronate.
Changes in upper gastrointestinal symptoms after 6 months of treatment (data not shown) Upper GI symptoms (heartburn, epigastralgia, and epigastric fullness) were evaluated using the Izumo scale questionnaire [16].

At baseline, a higher percentage of patients who switched over from alendronate had GI symptoms compared to those who switched over from risedronate or daily doses of minodronate. The use of concomitant gastrointestinal agents for GI symptoms was similar among the prior BP treatment subgroups, with no significant differences.

In the Switch group, the mean Izumo scale scores for the three GI symptoms significantly improved 1 month after treatment and at subsequent time points $(p<0.05)$, with the exception of epigastric fullness at 2 months after treatment. By contrast, in the Continue group, the mean Izumo scale scores for epigastralgia and epigastric fullness were stable over the 6month study period, while the mean scores for heartburn tended to improve, with statistically significant differences at 3 and 6 months after treatment compared to baseline $(p<0.05$ and $p<0.01$, respectively).

\section{Treatment persistence of MIN $50 \mathrm{mg}$}

Treatment persistence in the Switch and Continue groups during the 6-month study period in summarized using survival curves in Fig. 5. Overall, the persistence rate after 6 months of treatment was higher in the Switch group (89.8\%) than that in the Continue group ( $78.9 \% ; p<0.003$, log-rank test). During 


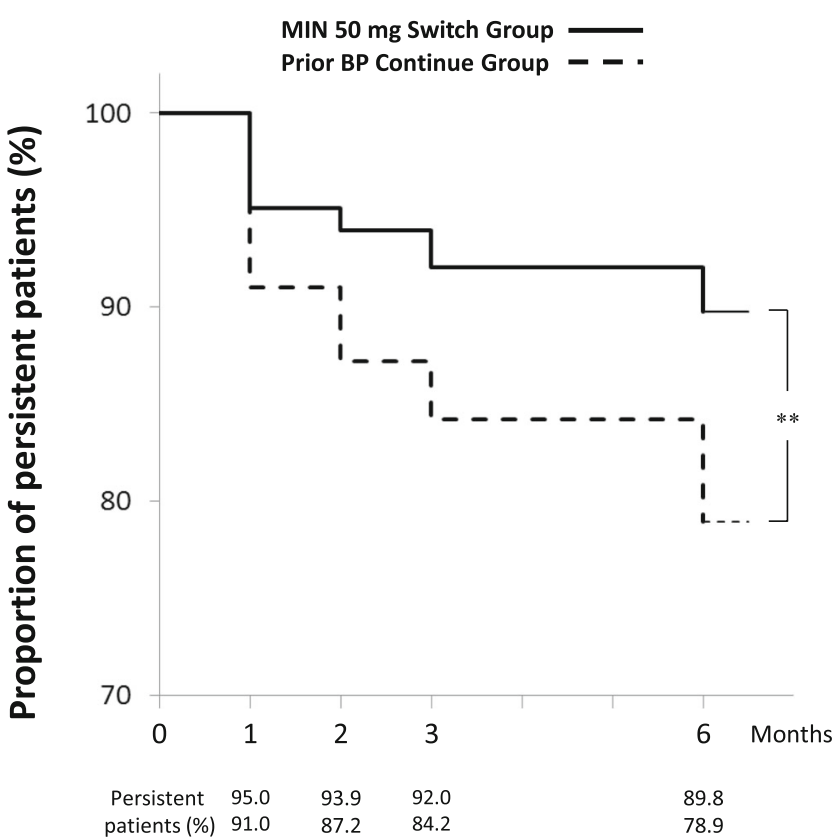

Fig. 5 Treatment persistence in the Switch and Continue groups. Proportion of persistent patients for each treatment was evaluated at 1, 2, 3, and 6 months of treatment. $* * p<0.01$, significantly different between groups as analyzed by log-rank test

the study period, 9 patients (3.4\%) in the Switch group hoped to switch back to their previous BP products, while 19 patients $(14.3 \%)$ in the Continue group hoped to switch over to MIN $50 \mathrm{mg}$. Regarding expectations (baseline) and actual impressions (after 6 months of treatment) of the once-monthly regimen, $87.3 \%$ of patients ( 220 of 252 ) expected less frequent dosing to be more convenient, and $77.9 \%$ of patients (180 of 231) actually had such an impression. However, the impression that "monthly schedule fits lifestyle better" drastically increased from baseline $(5.6 \%, 14$ of 252) to the end of the study $(32.5 \%, 75$ of 231$)$.

\section{Discussion}

We conducted a questionnaire-based study on drug preference for once-monthly oral bisphosphonate (MIN $50 \mathrm{mg}$ ) and persistence of MIN $50 \mathrm{mg}$ in Japanese patients with osteoporosis currently treated with daily or weekly BPs. Based on patients' preference, study patients were allocated to either the "Switch" group, consisting of patients who were willing to switch over to MIN $50 \mathrm{mg}$ from their current therapies, or the "Continue" group, consisting of patients who wanted to continue their current therapies. The bone mineral densities, bone turnover markers, time courses of low back pain and upper GI symptoms, and treatment persistence were compared between the treatment groups to evaluate the usefulness of oncemonthly MIN $50 \mathrm{mg}$ treatment.
About $65 \%$ of study patients were willing to switch to MIN $50 \mathrm{mg}$ among both patients treated with daily BPs and weekly BPs. In addition, at the end of the study, almost all of the study patients in the Switch group responded via questionnaire that they were "willing to continue MIN $50 \mathrm{mg}$." Once-monthly treatments such as MIN $50 \mathrm{mg}$ will be a powerful option for these patients. Indeed, the treatment persistence of MIN $50 \mathrm{mg}$ was significantly higher than that in the Continue group consisting of patients treated with daily or weekly BP products, and therefore, the once-monthly treatment should improve patient persistence.

Almost all the patients treated with BP products whose bone turnover marker levels exceeded the normal range at baseline achieved normal levels after switching to MIN $50 \mathrm{mg}$ (Fig. 3). This finding suggests a superior bone resorption inhibitory effect of MIN $50 \mathrm{mg}$. In addition, MIN $50 \mathrm{mg}$ was not associated with an unwanted reduction in bone turnover markers among patients whose marker levels were already normal, indicating that MIN $50 \mathrm{mg}$ treatment is an ideal solution for improving bone turnover markers.

While many reports have indicated the bone densityincreasing effects of switching to daily minodronate from other BPs [11, 17-19], our study further confirmed that switching to once-monthly minodronate from other BPs significantly increased the bone density of the lumbar spine and distal radius (Fig. 2), suggesting that once-monthly minodronate $50 \mathrm{mg}$ will be a powerful alternative for osteoporosis treatment.

While daily minodronate has been reported to alleviate low back pain [19], this study revealed that once-monthly MIN $50 \mathrm{mg}$ also achieved positive results. Prompt effects of MIN $50 \mathrm{mg}$ on low back pain after switchover from prior BPs (Fig. 4) suggest the contribution of minodronate-specific inhibitory action on the $\mathrm{P} 2 \mathrm{X}_{2 / 3}$ receptor $[20,21]$, which is expressed in primary sensory neurons that mediate nociception and are implicated in neuropathic and inflammatory pain responses [22].

We have already reported that daily minodronate treatment induced fewer GI symptoms in comparison with weekly alendronate treatment [19]. As expected from this prior report, the GI symptoms induced by weekly alendronate were resolved statistically significantly within 1 month after switchover from alendronate to MIN $50 \mathrm{mg}$ (data not shown), suggesting that once-monthly minodronate may also induce fewer GI symptoms (heartburn, epigastralgia, and epigastric fullness). MIN $50 \mathrm{mg}$ is highly likely to improve both convenience and treatment persistence because it alleviates low back pain and results in fewer GI symptoms after switchover from conventional BP products.

There are limitations in this study. This is an open-label observational study involving small number of patients, and the patients are not randomized but are assigned to two groups by their preference. Therefore, there is a selection bias in being enrolled in the two groups. 
Because MIN $50 \mathrm{mg}$ alleviates low back pain, reduces bone turnover markers, increases bone mineral density and treatment persistence, and induces fewer GI symptoms after switchover from conventional BP products, the drug may provide patients with a more convenient treatment option and enhance long-term treatment persistence with the therapy.

Acknowledgments We thank DS Pharma Biomedical Co., Ltd for technical support.

Conflicts of interest Akinori Sakai, Satoshi Ikeda, Nobukazu Okimoto, Hidehiro Matsumoto, Kitau Teshima, Yuichi Okazaki, Fumio Fukuda, Shinobu Arita, Hiroshi Tsurukami, Masato Nagashima, and Toru Yoshioka received research support from Astellas Pharma Inc. (Tokyo, Japan); the sponsor was not involved in the design of study, the enrollment of patients, or the collection, analysis, or interpretation of data. The authors were supported in the editing and writing of this manuscript by Dr. Tsumura with EPS Corporation (Tokyo, Japan) and funded by Astellas. The authors are fully responsible for the content and editorial decisions of this manuscript.

Open Access This article is distributed under the terms of the Creative Commons Attribution Noncommercial License which permits any noncommercial use, distribution, and reproduction in any medium, provided the original author(s) and the source are credited.

\section{References}

1. Watts NB, Bilezikian JP, Camacho PM, Greenspan SL, Harris ST, Hodgson SF, Kleerekoper M, Luckey MM, McClung MR, Pollack RP, Petak SM, Osteoporosis Task Force AACE (2010) American Association of Clinical Endocrinologists Medical Guidelines for Clinical Practice for the diagnosis and treatment of postmenopausal osteoporosis. Endocr Pract 16(Suppl 3):1-37

2. North American Menopause Society (2010) Management of osteoporosis in postmenopausal women: 2010 position statement of the North American Menopause Society. Menopause 17(1):25-54

3. Orimo H, Nakamura T, Hosoi T, Iki M, Uenishi K, Endo N, Ohta H, Shiraki M, Sugimoto T, Suzuki T, Soen S, Nishizawa Y, Hagino H, Fukunaga M, Fujiwara S (2012) Japanese 2011 guidelines for prevention and treatment of osteoporosis - executive summary. Arch Osteoporos 7(1-2):3-20

4. Yood RA, Emani S, Reed JI, Lewis BE, Charpentier M, Lydick E (2003) Compliance with pharmacologic therapy for osteoporosis. Osteoporos Int 14(12):965-968

5. Weycker D, Macarios D, Edelsberg J, Oster G (2007) Compliance with osteoporosis drug therapy and risk of fracture. Osteoporos Int 18(3):271-277

6. Rabenda V, Mertens R, Fabri V, Vanoverloop J, Sumkay F, Vannecke C, Deswaef A, Verpooten GA, Reginster JY (2008) Adherence to bisphosphonates therapy and hip fracture risk in osteoporotic women. Osteoporos Int 19(6):811-818

7. Siris ES, Harris ST, Rosen CJ, Barr CE, Arvesen JN, Abbott TA, Silverman S (2006) Adherence to bisphosphonate therapy and fracture rates in osteoporotic women: relationship to vertebral and nonvertebral fractures from 2 US claims databases. Mayo Clin Proc 81(8):1013-1022

8. Curtis JR, Westfall AO, Cheng H, Lyles K, Saag KG, Delzell E (2008) Benefit of adherence with bisphosphonates depends on the age and fracture type: results from an analysis of 101,038 new bisphosphonate users. J Bone Miner Res 23(9):1435-1441

9. Silverman SL, Gold DT (2008) Compliance and persistence with osteoporosis therapies. Curr Rheumatol Rep 10(2):118-122

10. Chatani Y (2005) Minodronic acid hydrate as a new therapeutic agent for osteoporosis. Clin Calcium 15(1):9-14, Article in Japanese

11. Kubo T, Shimose S, Matsuo T, Fujimori J, Ochi M (2010) Minodronate for the treatment of osteoporosis. Drugs Today (Barc) 46(1):33-37

12. Sorbera LA, Castañer J, Leeson PA (2002) Minodronic acid. Drugs Future 27(10):935-941

13. Tanishima S, Morio Y (2013) A review of minodronic acid hydrate for the treatment of osteoporosis. Clin Interv Aging 8:185-189

14. Okazaki R, Hagino H, Ito M, Sone T, Nakamura T, Mizunuma H, Fukunaga M, Shiraki M, Nishizawa Y, Ohashi Y, Matsumoto T (2012) Efficacy and safety of monthly oral minodronate in patients with involutional osteoporosis. Osteoporos Int 23(6):1737-1745

15. Kumamoto K, Nakamura T, Suzuki T, Gorai I, Fujinawa O, Ohta H, Shiraki M, Yoh K, Fujiwara S, Endo N, Matsumoto T (2010) Validation of the Japanese Osteoporosis Quality of Life Questionnaire. J Bone Miner Metab 28(1):1-7

16. Furuta K, Ishihara S, Sato S, Miyake T, Ishimura N, Koshino K, Tobita H, Moriyama I, Amano Y, Adachi K, Ohta A, Kinoshita Y (2009) Development and verification of the Izumo Scale, new questionnaire for quality of life assessment of patients with gastrointestinal symptoms. Nihon Shokakibyo Gakkai Zasshi 106(10):14781487, Article in Japanese

17. Hagino H, Shiraki M, Fukunaga M, Nakano T, Takaoka K, Ohashi Y, Nakamura T, Matsumoto T (2012) Three years of treatment with minodronate in patients with postmenopausal osteoporosis. J Bone Miner Metab 30(4):439-446

18. Yoshioka T, Okimoto N, Okamoto K, Sakai A (2013) A comparative study of the effects of daily minodronate and weekly alendronate on upper gastrointestinal symptoms, bone resorption, and back pain in postmenopausal osteoporosis patients. J Bone Miner Metab 31(2): $153-160$

19. Matsumoto T, Hagino H, Shiraki M, Fukunaga M, Nakano T, Takaoka K, Morii H, Ohashi Y, Nakamura T (2009) Effect of daily oral minodronate on vertebral fractures in Japanese postmenopausal women with established osteoporosis: a randomized placebocontrolled double-blind study. Osteoporos Int 20(8):1429-1437

20. Kakimoto S, Nagakura Y, Tamura S, Watabiki T, Shibasaki K, Tanaka S, Mori M, Sasamata M, Okada M (2008) Minodronic acid, a third-generation bisphosphonate, antagonizes purinergic P2X2/3 receptor function and exerts an analgesic effect in pain models. Eur J Pharmacol 589(1-3):98-101

21. Yamagami Y, Mashiba T, Iwata K, Tanaka M, Nozaki K, Yamamoto $\mathrm{T}$ (2013) Effects of minodronic acid and alendronate on bone remodeling, microdamage accumulation, degree of mineralization and bone mechanical properties in ovariectomized cynomolgus monkeys. Bone 54(1):1-7

22. Mo G, Bernier LP, Zhao Q, Chabot-Doré AJ, Ase AR, Logothetis D, Cao CQ, Séguéla P (2009) Subtype-specific regulation of P2X3 and $\mathrm{P} 2 \mathrm{X} 2 / 3$ receptors by phosphoinositides in peripheral nociceptors. Mol Pain 5:47 